\title{
Mechanical and thermal stress evaluation of PEEK prefabricated post with different head design in endodontically treated tooth: 3D-finite element analysis
}

\author{
Rawa Omar IBRAHIM ${ }^{1}$, Abdulsalam Rashid AL-ZAHAWI ${ }^{1}$ and Laith Abed SABRI ${ }^{2}$ \\ ${ }^{1}$ Conservative Department, College of Dentistry, University of Sulaimani, Iraq \\ ${ }^{2}$ Department of Mechatronics, Al-Khwarizmi College of Engineering, University of Baghdad, Iraq \\ Corresponding author, Rawa Omar IBRAHIM; E-mail: rawa.ibrahim@univsul.edu.iq
}

\begin{abstract}
An endodontic post is required to retain and support the core restoration in case of insufficient remaining coronal dentin after root canal therapy. This study analyzed the biomechanical and thermal behavior of PEEK prefabricated post after choosing the head design that produces the least amount of stress on the core and remaining tooth structure. These results were compared with the most common commercially available prefabricated post, which is titanium and glass fiber post. Thus a CBCT scanning of a maxillary central incisor with its supporting structure was used to construct a 3D solid model of an endodontically treated teeth for finite element analysis (FEA). The restored tooth with the spherical head design of PEEK prefabricated post yielded a more benign stress distribution and repairable failure mode on the crown, luting cement, core, and dentin under both mechanical and thermal loads, followed by glass fiber post and titanium post respectively.
\end{abstract}

Keywords: Finite element analysis, Endodontic post, PEEK, Mechanical and thermal stress distribution

\section{INTRODUCTION}

A successful restoration of endodontically treated teeth has a major impact on the survival of the tooth. The remaining coronal tooth structure, along with the position of the tooth in the arch, and the esthetic requirement will determine the type of restoration indicated; whether restored directly or reinforced by post with core and crown ${ }^{1-3)}$. Cast posts have been utilized for many decades owing to the fact that they follow the shape of the root cavity in the most adequate way. More recently, prefabricated posts have become more popular since they can provide satisfactory results with limited preparatory work while saving time and reducing cost ${ }^{4,5}$.

Nowadays with increased demands toward a heightened awareness of aesthetics, tooth-colored metalfree post-core systems have become the preferred choice in restoring pulpless teeth ${ }^{5}$. According to previous studies, a post like fiber post with a relatively low elastic modulus enables more uniform distribution of the occlusal load on root dentin and cement interfaces ${ }^{6}$, and transmit the position of maximum stress above the level of the bone at the neck of the tooth ${ }^{7,8)}$. However, fiber posts have lower elastic moduli than those of metal alloy posts, but still higher than the root canal dentin ${ }^{9)}$, especially the elastic modulus of dentin decrease after root canal treatment ${ }^{10)}$. Therefore; the use of post material with elastic modulus less than dentin like PEEK (Polyetheretherketone) distributes the stress in dentin more uniformly and produce repairable type of failure at the neck of the tooth when fracture occurred under excessive load.

Color figures can be viewed in the online issue, which is available at J-STAGE.

Received Feb 15, 2020: Accepted Jun 16, 2020

doi:10.4012/dmj.2020-053 JOI JST.JSTAGE/dmj/2020-053
PEEK is a tooth-colored synthetic thermoplastic polymer, which exhibits appropriate mechanical and shock-absorbing properties ${ }^{11,12}$, with the ability of bonding to both the dentin and resin cement ${ }^{13,14)}$, make it suitable material to be used as a post especially the retention of the post is achieved with adhesive luting cement instead of the thread as later introduces great stresses within the dentin ${ }^{2}$.

In recent years, after successful applications of PEEK as a primary substitute for metallic components in the field of orthopedics and trauma, it has been introduced to dentistry ${ }^{15,16}$. An article reported using Modified PEEK as endocrown ${ }^{17}$, another study evaluated possible application PEKK (Polyetherketoneketone) as a cast post ${ }^{9}$, which is a similar material to PEEK with a minor difference in thermal properties and compression strength $^{18,19)}$.

Regarding the design of prefabricated posts, a wide range of recommendations are found in the literature; as general rule increasing the length of the post enhances the retention and the resistance of the post. However, long post jeopardizes the apical seal as a small volume of obturation material remains in the root canal to act as a barrier against microbial penetration along the root canal to prevent periapical inflammation ${ }^{20,21)}$. The post diameter has less effect than the post length on retention ${ }^{22}$ and the enlargement of the root canal space leads to unrepairable failure and cannot be compensated ${ }^{23}$. Recently proved that prefabricated post head design also affects the stress distribution in the core and crown structure ${ }^{24)}$.

Normally teeth are encountered stress loadings during the mastication process ${ }^{25,26)}$ and thermal stresses during the hot and cold beverage and food intake ${ }^{27,28)}$. These repeated effects of thermal fluctuations and 
mechanical loadings on endodontically restored teeth should be analyzed as a whole, in order to locate the areas of high-stress concentration which subsequently jeopardize the long-term survival rate of bonding between layers of restoration and remaining tooth structure leading to coronal leakage, degradation of the tooth tissues and restoration ${ }^{29,30)}$.

Fortunately, with rapid improvements in computer technology, finite element analysis (FEA) enables the user to accurately simulate a complex design like a post-crown endodontic restoration system and natural condition of oral cavity by entering various environmental parameters and tissue properties, overcoming the ethical issues and difficulties regarding medical studies ${ }^{31}$. The majority of the FE based studies in literature focuses on biomechanical behavior of post-endodontic restoration system under mechanical loadings ${ }^{25,32-35)}$. However, a limited number of studies in literature examined the effect thermal loading on stresses that created as a result of different thermal properties of the materials and remaining tooth structure ${ }^{36-39}$. To the extent of our knowledge, there is no previous study in the literature focusing on the effect of PEEK material under oral thermal stress.

Of the modeling techniques used in this study, a cone-beam computed tomography (CBCT) based modeling was used to obtain more accurate mimicking of dental structures and restorative materials ${ }^{40}$. Unlike most previous studies, which used simplified model of $2 \mathrm{D}$ or $3 \mathrm{D}$ geometry, neglecting some parts, or fixing the tooth inside the block of bone $e^{9,25,41)}$, a realistic modeling of the surrounding maxillary bone with a proper volumetric and geometric accuracy of tooth socket, cancellous and, cortical bone is important in the term of boundary conditions as it has direct effect on in stress distributions results ${ }^{42,43)}$.

The main objective of this study was to investigate the biomechanical behavior of prefabricated post made from PEEK after choosing the head design that produces the least amount of stress on the core and remaining tooth structure by 3D FEA. In addition, a transient thermal FEA simulating hot and cold liquid exposure was used to investigate variations in thermal stresses in different tissues with the studied posts. These results were compared with prefabricated titanium and fiber post.

\section{MATERIALS AND METHODS}

$3 D$ modeling of geometry

A CBCT scan of a 28-year old volunteer with normal occlusion was acquired with (NewTom Giano HR, Cefla, Italy) after taking written informed consent from the patient, as data from CBCT can be used accurately to reconstruct a $3 \mathrm{D}$ tooth geometry with high linear, volumetric, and geometric measurements ${ }^{43,44}$. A series of image datasets were utilized with total of 185 slices, voxel dimension of $68 \mathrm{~mm}$, field of view $11 \times 8 \mathrm{~cm}$, and a slice thickness of $0.3 \mathrm{~mm}$, then saved in DICOM format, after that, imported into image-processing software
(Mimics, version 21, Materialise, Leuven, Belgium) for construction of 3D surface model and segmenting the scanned objects into separate elements. The size of the 3D geometry was reduced by applying global image thresholding, the maxilla in the area related to the central incisor with its supporting structure was selected and segmented. Then the data transferred as (STL) files into Autodesk Meshmixer software version 3.0 (Autodesk, Germany) to view and assemble the dimensions of the tooth with its supporting structure, where mesh improvement and refinement was carried out.

The dimensions of the tooth were modified based on the anatomical measurements suggested by Wheeler dental anatomy ${ }^{45}$. The morphology of enamel, dentin, and pulp was adjusted according to previous studies ${ }^{46,47)}$. The thickness of cementum is considered to be $50 \mathrm{um}$ in the cervical area and increased gradually to $200 \mu \mathrm{m}$ in the apical are ${ }^{48)}$, while the periodontal ligament covered $11 \mathrm{~mm}$ of root surface with a thickness of $0.18 \mathrm{~mm}^{49,50)}$. The supporting bone was divided into lamina dura, cancellous bone, and cortical bone, which re-designed to standardize the geometry of each component $t^{51-54}$.

After the setup of the basic model of the sound incisor, a second modeling step was performed to obtain endodontically treated tooth restored with classical Allceramic crown with a prefabricated post and a composite resin core as shown in Fig. 1.

The solid model was altered through a simulation of a clinical preparation protocol in extensively damaged endodontically treated teeth. The crown portion of the model was removed until $2 \mathrm{~mm}$ above the cementoenamel junction (CEJ) to represent the ferrule effect.

The length of gutta-percha assumed to be $5 \mathrm{~mm}^{55,56)}$, following the shape of the pulp, while the resin cement layer was created occupying the space between the post and dentin with $120 \mu \mathrm{m}$ thickness ${ }^{57)}$.

The crown was modeled based on the enamel structure of the natural maxillary incisor and the same technique was applied for the core, where it was developed following the shape of dentin, after that the undercut of the core was removed and 6-degree

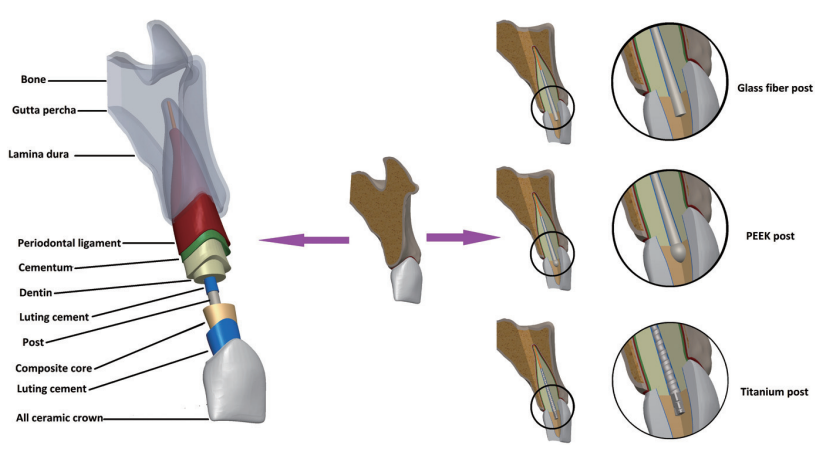

Fig. 1 Exploded mode and constructed geometry models for three types of post integrated into endodontically treated maxillary central incisor. 
angulation was created to follow standard general protocol for all-ceramic crown preparation ${ }^{58)}$, finally a layer of luting cement was created with $25 \mu \mathrm{m}$ thickness between the core and the crown ${ }^{59)}$.

Accordingly, three types of prefabricated posts were simulated as follow:

Group 1: Prefabricated titanium post (Unimetric $0.8 \mathrm{~mm}$, Dentsply, Switzerland).

Group 2: Glass fiber post (Radix ${ }^{\circledR}$ Fiber Post, Dentsply).

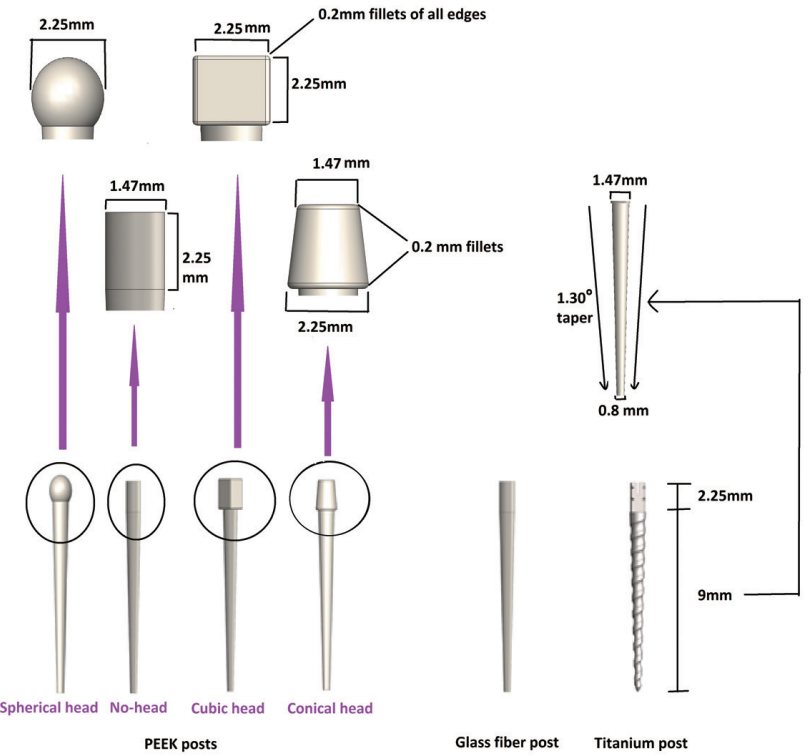

Fig. 2 Geometry of endodontic posts.
Group 3: Proposed PEEK post (PEEK optima dental disc, Juvora, Switzerland).

To evaluate the influence of the post materials only, excluding the influence of the size, the main dimensions of the posts kept constant and modeled based on the existing dimensions obtained from a manufacturer (size 2L, length $9 \mathrm{~mm}$, width of $0.8 \mathrm{~mm}$ at apical end, 1.47 $\mathrm{mm}$ cervically, length of the head $2.25 \mathrm{~mm}, 1.3^{\circ}$ passive taper) as in Fig. 2.

Four designs of proposed prefabricated PEEK head were tested in the work as shown in Fig. 2, to select the head design with the least stress concentration in the core material and the internal surface of dentin.

The titanium post is considered as an active post unlike fiber and PEEK, which cannot be bonded chemically to dentin, so the thread was generated on the surface of the post with the exact geometry of the manufacturer.

The materials used in the present simulation were assumed to be homogenous, isotropic and linear elastic. Since the analysis was performed for two purposes, mechanical and thermal properties of all materials (Young's modulus, Poisson's ratio, density, specific heat, thermal expansion coefficient, and thermal conductivity) were defined for every part of the assembly according to previous literature data ${ }^{41,60-64)}$, and have been presented in Table 1.

After constructing each part as a solid geometry, Para solid XT file, we will be able to assemble the whole model, then the assembled model imported to ANSYS software (Ansys, Houston, TX, USA). In ANSYS the mechanical and thermal properties in the Table 1 of all of the parts were introduced. To do the mechanical and

Table 1 Thermal and mechanical properties of materials and tooth tissues

\begin{tabular}{|c|c|c|c|c|c|c|}
\hline Material & $\begin{array}{l}\text { Elastic } \\
\text { modulus } \\
(\mathrm{GPa})\end{array}$ & $\begin{array}{l}\text { Poisson's } \\
\text { ratio }\end{array}$ & $\begin{array}{l}\text { Density } \\
\left(\mathrm{g} / \mathrm{cm}^{3}\right)\end{array}$ & $\begin{array}{l}\text { Specific heat } \\
{\left[\mathrm{J} /\left(\mathrm{g}^{\circ} \mathrm{C}\right)\right]}\end{array}$ & $\begin{array}{c}\text { Thermal } \\
\text { expansion } \\
\left(1 /{ }^{\circ} \mathrm{C}\right)\end{array}$ & $\begin{array}{l}\text { Conductivity } \\
{\left[\mathrm{J} /\left(\mathrm{s} \mathrm{mm}^{\circ} \mathrm{C}\right)\right]}\end{array}$ \\
\hline Dentin & 18.6 & 0.31 & 2.14 & 1.172 & $1.06 \times 10^{-5}$ & $0.63 \times 10^{-3}$ \\
\hline Cementum & 15.5 & 0.31 & 2.06 & 0.824 & $1.1 \times 10^{-5}$ & $0.62 \times 10^{-3}$ \\
\hline Periodontal ligament & 0.069 & 0.45 & 1.04 & 2.290 & $1.06 \times 10^{-5}$ & $0.59 \times 10^{-3}$ \\
\hline Cortical bone & 14.7 & 0.30 & 2.06 & 1.26 & $1.0 \times 10^{-5}$ & $0.38 \times 10^{-3}$ \\
\hline Cancellous bone & 0.49 & 0.38 & 0.62 & 1.16 & $1.0 \times 10^{-5}$ & $0.38 \times 10^{-3}$ \\
\hline Resin luting cement & 7.7 & 0.30 & 1.10 & 0.824 & $3 \times 10^{-5}$ & $1.091 \times 10^{-3}$ \\
\hline Guttapercha & 0.69 & 0.45 & 2.70 & 1.042 & $16.2 \times 10^{-5}$ & 332.4 \\
\hline $\begin{array}{l}\text { Composite resin } \\
\text { (Hybrid/Ivoclar-Vivadent) }\end{array}$ & 12 & 0.30 & 2.26 & 1.40 & $3.94 \times 10^{-5}$ & $197 \times 10^{-3}$ \\
\hline Ceramic crown (E-max) & 91 & 0.23 & 2.40 & 989 & $1.7 \times 10^{-5}$ & 1.467 \\
\hline Glass fiber post & 40 & 0.30 & 2.50 & 0.26 & $0.85 \times 10^{-5}$ & $1.3 \times 10^{-3}$ \\
\hline PEEK optima post & 4.2 & 0.36 & 1.30 & 1.700 & $52 \times 10^{-5}$ & $0.25 \times 10^{-3}$ \\
\hline Titanium post & 112 & 0.30 & 4.51 & 11.9 & $54 \times 10^{-5}$ & $21.9 \times 10^{-3}$ \\
\hline
\end{tabular}


thermal analysis, a proper mesh was generated and the initial condition, boundary condition, and loading were introduced in ANSYS.

\section{Biomechanical stress analysis}

All prepared assembly has meshed for finite element simulations. 3D 10-node tetrahedral elements were used to be compatible with model irregular meshes and complex geometries of dental structures ${ }^{60)}$. The standard convergence tests were applied to all models in each test stage, the mesh was considered satisfactory when even with decreasing the size of elements, and the highest stress levels remained constant to represent the original geometry accurately.

For simulating the interface between model components, bonded contact was prescribed along with all model interfaces. The lateral surface of the maxillary bone was assumed to be rigidly fixed in the $\mathrm{x}, \mathrm{y}$, and $\mathrm{z}$ directions.

A static bite load with a constant intensity of $100 \mathrm{~N}$ was applied $3 \mathrm{~mm}$ apical to the incisal margin of the palatal surface of the crown at an angle of 45 degrees relative to the longitudinal axis of the tooth for calculating stress distribution in normal occlusal contact with the antagonist tooth ${ }^{26,42)}$.

\section{Thermal stress analysis}

A transient thermal FEA was conducted as a timedependent behavior of applied thermal loads on the outer surface of the crown to represent thermal loadings during the hot and cold liquid/food intake.

The initial temperature of the entire assembly was set to $36.5^{\circ} \mathrm{C}$ to simulate the temperature inside the oral cavity $^{65)}$.

For each model, the outer surface of the crown was subjected to $60^{\circ} \mathrm{C}$ for $2 \mathrm{~s}$ corresponding to the normal duration of exposure to hot thermal loading. After that, the temperature was relaxed to retrieve an oral cavity temperature of $36.5^{\circ} \mathrm{C}$ within $5 \mathrm{~s}$, this analysis was repeated 3 times for 5 -s-time intervals. For the cold thermal simulation, the same procedure was performed for a temperature of $5^{\circ} \mathrm{C}$. These thermal loads and time intervals were established based on the measurements from previous literature ${ }^{30,60,64)}$, while the FEA should not be used to represent long term effects of low-order heating or cooling of the teeth that might occur during eating or drinking, because is not possible to give a large number of typical results, as a few representative situations will be noted ${ }^{66)}$.

The convection coefficient values on the outer surface of the all-ceramic crown were assumed to be constant and equal to $7.37 \times 10^{-4}\left[\mathrm{~J} /\left(\mathrm{s} \mathrm{mm}^{2} \mathrm{~K}\right)\right]$ for $5^{\circ} \mathrm{C}$ sink temperature describe the consumption of cold liquid and, $5.0 \times 10^{-4}$ $\left[\mathrm{J} /\left(\mathrm{s} \mathrm{mm}^{2} \mathrm{~K}\right)\right]$ for $60^{\circ} \mathrm{C}$ sink temperature assumes the hot liquid drinking ${ }^{28,66)}$.

\section{RESULTS}

\section{Mechanical load}

The results of the stress distributions are presented in contour graphics with a color scale in Megapascal (MPa), with maximum Equivalent von Mises (EVM) stress concentration in each dental model component.

The influence of PEEK post with four head designs was taken into account on each individual component of the restored system by recording maximum EVM stress distributions. As in Fig. 3a, the highest stresses were found in cubic head design followed by conical and no-head design, while the spherical head presented with the lowest value in each component. It is possible to note that the main effect of the head design was in composite core with the peak stress of $57.87 \mathrm{MPa}$ for the cubic design and only $7.75 \mathrm{MPa}$ for the spherical head design as shown in Fig. 3b. Based on these results, the spherical head design was chosen as the proposed design of the PEEK prefabricated post.

For each component of all simulations, both the

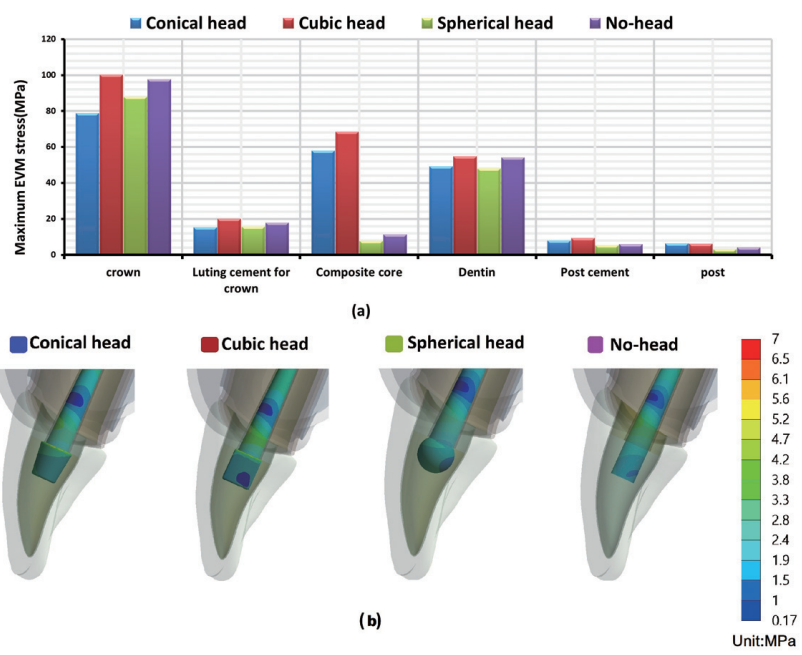

Fig. 3 (a) maximum values of EVM stresses on model layers for each head design of PEEK post, (b) color code plot of the tested post head design.

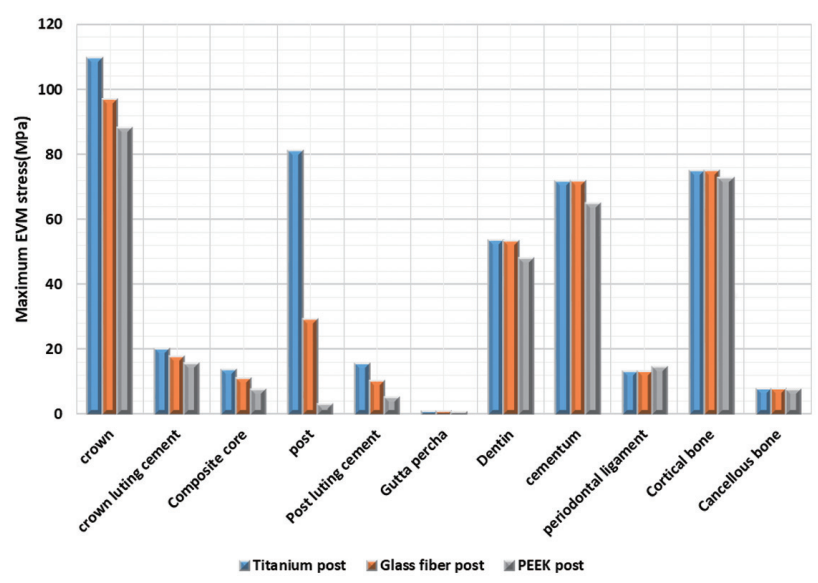

Fig. 4 Maximum values of EVM stress in the dental post-endodontic restoration system with different posts. 
stress contour plot and the maximum stress distribution were reported.

The maximum values of EVM stress in the dental post-endodontic restoration system with different posts were shown in Fig. 4. In general, all systems show symmetric behaviors regarding the distribution of stress on each part of the model with higher values of a titanium post, followed by glass fiber post and PEEK posts. The major value differences were found on the post with a peak value of $81.11 \mathrm{MPa}$ of a titanium post, 29.26 $\mathrm{MPa}$ for glass fiber post, and only 3.17 MPa of PEEK post.

As it can be seen in the contour plot Fig. 5, in all simulations the peak stress concentrated on the lingual surface just below the cervical line for dentin, and on the labial cervical edge of the crown and luting cement, while for composite cores the maximum EVM were located on the incisal tip lingually. On the other hand, the position of peak stresses was different in both post and post cement between the three simulations.

Since the position of maximum stress is crucial clinically to decide the type of failure in endodontic post system either repairable or not, stress distribution line was created at the interface of dentine to cemented post along the middle plane in longitudinal axis cervicoapically of the three models as shown in Fig. 6. In both fiberglass and PEEK post cases, the maximum values of EVM stress were located above the bone level in the ferrule area of dentin as in Fig. 6a, while in titanium post case, the stress distribution was higher than that of the others and located at the middle third of the root.
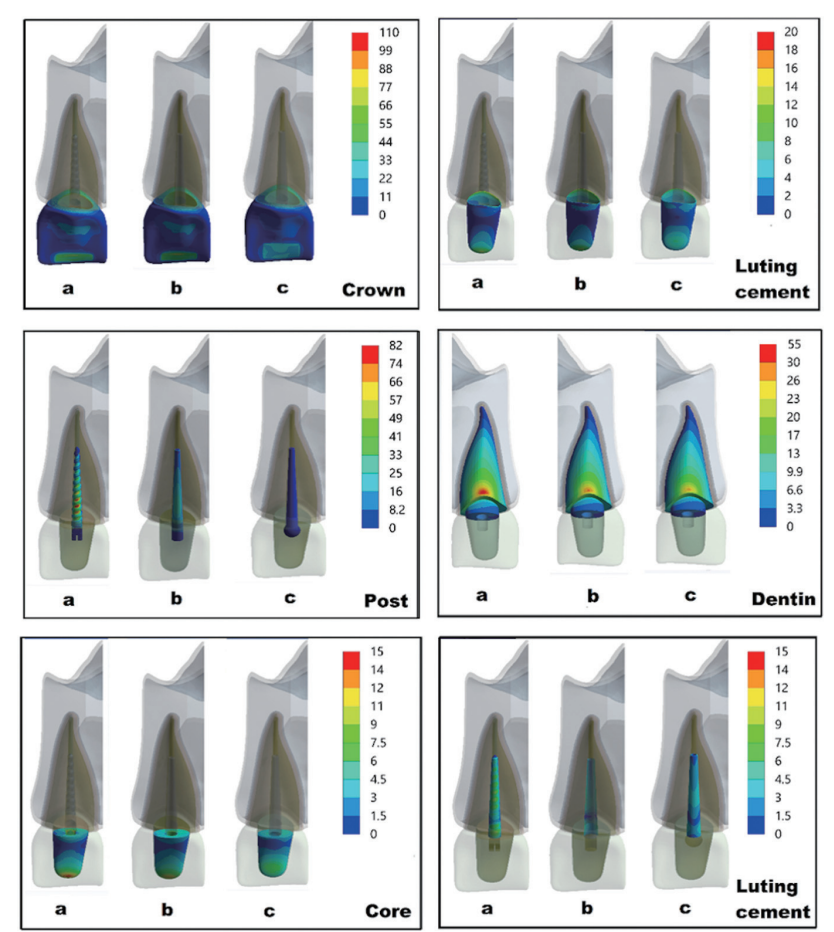

Fig. 5 EVM stress contour plots in MPa of components of (a): Titanium post (b): Glass fiber post (c): PEEK post.
The fluctuation of the stresses in Fig. $6 \mathrm{~b}$ was due to the changes in the geometry for the Titanium thread.

\section{Thermal load}

The results of temperature distribution from the transient thermal analysis are presented in Fig. 7. Six data points, A, B, C, D, E, and F were selected along a middle longitudinal plane to represent the variations in temperature distributions at different tissues as a function of time. The selection of the points was based on the results of the mechanical part of the study where

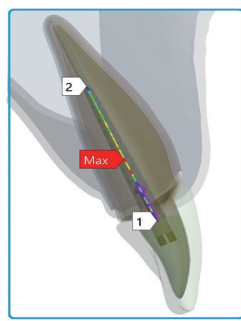

Titanium post —

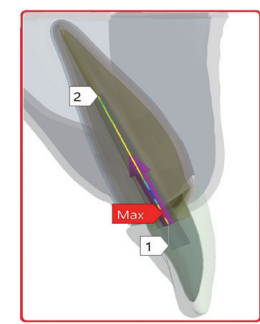

Fiber glass post -

(a)

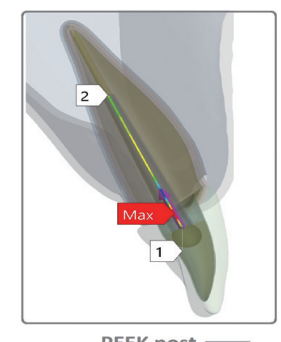

PEEK post

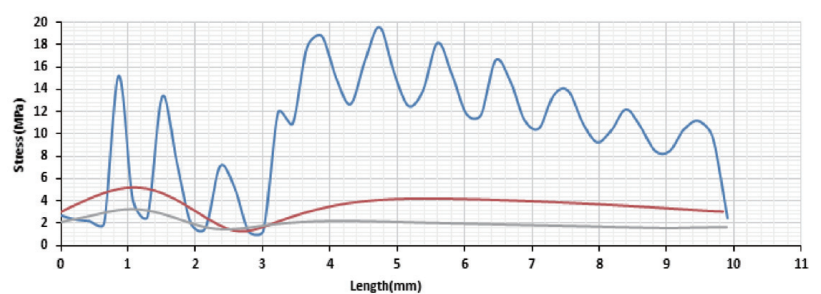

(b)

Fig. 6 (a) EVM stresses values along a vertical line at the interface of dentin and post cement from cervical to apical for the three models, (b) sagittal section views the position of maximum EVM along that line.

(a)
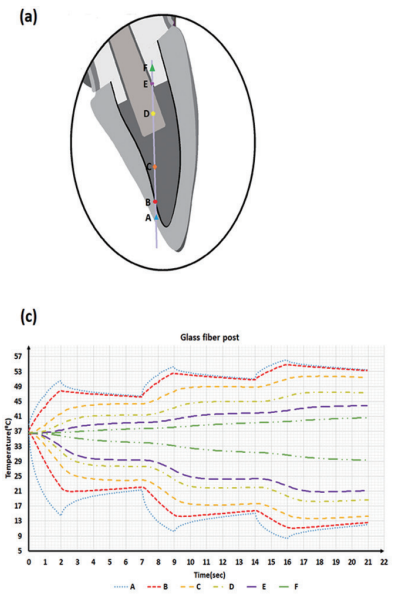
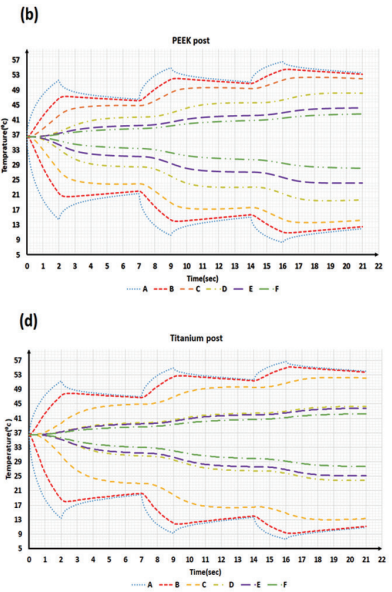

Fig. 7 Temperature distribution in selected points in all the models (a), temperature change per time in PEEK post group (b), temperature change per time in glass fiber post group(c), and temperature change per time in titanium post group (d). 
the type of post has an influence on these components of the model. It can be observed in the Fig. 7a set of twelve curves of temperature, corresponding to each point, these curves are therefore distributed in two subsets of six curves, one subset for hot exposure and the other for cold exposure.

Application of the hot thermal load on tooth restored with PEEK post increased the temperature in point $\mathrm{A}$ until $56.5^{\circ} \mathrm{C}$, while maximum temperatures through points B, C, D, E, and F were 54.4, 51.6, 46.4, 42.9 and $41.5^{\circ} \mathrm{C}$ respectively. For cold thermal application, the temperatures at point $\mathrm{A}$ reduced to $8.3^{\circ} \mathrm{C}$, while the minimum temperatures through points $\mathrm{B}, \mathrm{C}, \mathrm{D}, \mathrm{E}$, and $\mathrm{F}$ were $11,14.5,21.4,25.7$, and $39.5^{\circ} \mathrm{C}$ respectively as seen in Fig. $7 b$.

Temperature distributions of the tooth restored with glass fiber post are shown in Fig. 7c. The maximum and the minimum temperatures were found between points $\mathrm{A}$ and $\mathrm{F}$ with the range of 56.0 to $39.6^{\circ} \mathrm{C}$ for the hot application, while it varies between 8.3 to $30.6^{\circ} \mathrm{C}$ for the cold thermal loading.

Finally, for the tooth restored with Titanium post
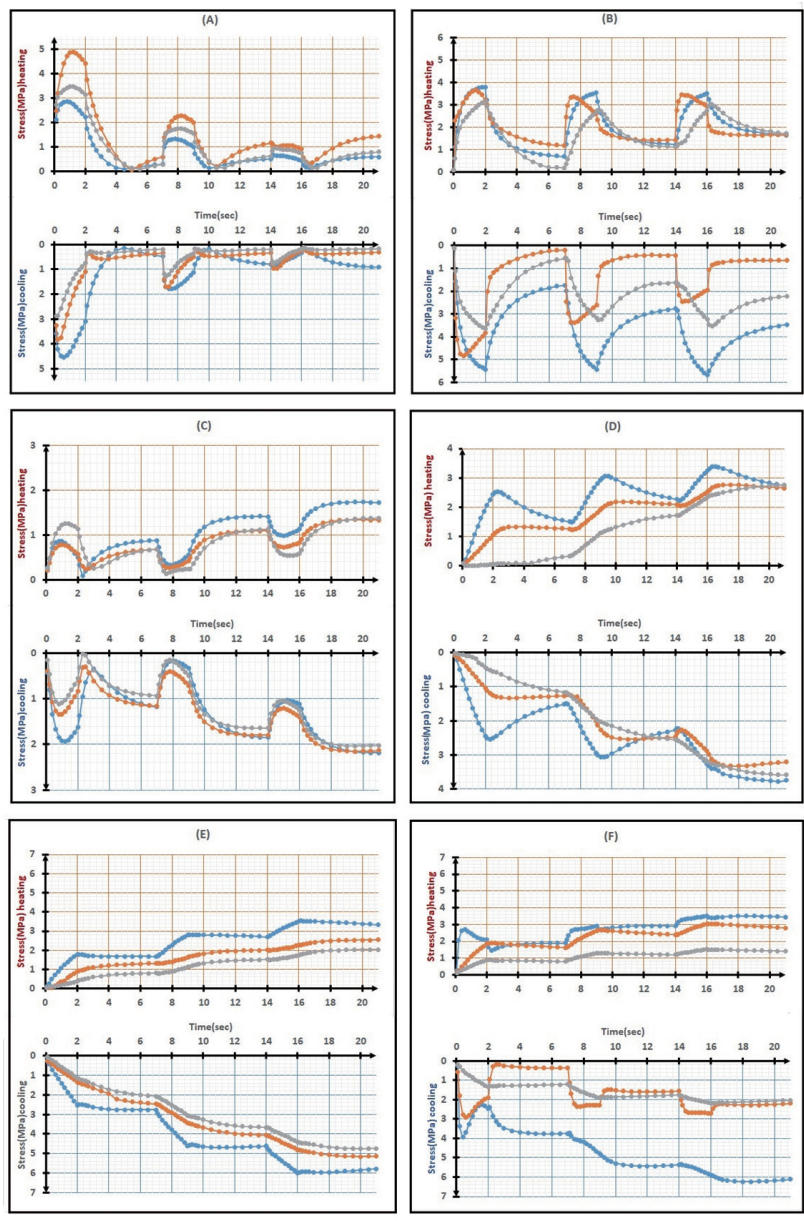

- Titanium post

$\multimap$ Glass fiber post $\longrightarrow$ PEEK post

Fig. 8 EVM stresses per time in the selected points after cold and hot applications of all post groups. the maximum temperature between point $\mathrm{A}$ and $\mathrm{F}$ were 56.7 to $41.2^{\circ} \mathrm{C}$, and the minimum temperature was 7.6 to $29.2^{\circ} \mathrm{C}$ for the same points as seen in Fig. $7 \mathrm{~d}$.

Accordingly, the maximum temperature gradient between the A to $\mathrm{F}$ data point after cold application was highest in the glass fiber group, followed by the PEEK post group, while the least temperature gradient was seen in titanium post.

Regarding the variation of stress distribution induced by the applied thermal loads among studied groups, EVM stress distribution of the measurement points (A to F) was measured as a function of time illustrated in Fig. 8.

Overall, as shown in Fig. 8, the cold loading induced more stresses than hot loading on the same point at the same time, additionally, the effect of the post type was more significant on the $\mathrm{D}, \mathrm{E}$, and F points.

The maximum EVM stress on the six tissue layers of each group was presented in Fig. 9 after thermal application, the group that restored with Titanium post introduced the highest maximum EVM stress on the core, post, post luting cement, and dentin. Followed by the group restored by fiber post and PEEK post respectively, while there was little or no difference between the groups in the crown and crown luting cement layers.

The positions of thermal stress distributions for the different study groups after the 21st second of heat and cold applications were summarized in Fig. 10. For all the groups, the largest stresses introduced in similar positions on different component, for example, the position the maximum EVM stress on the crown was located on the middle of palatine surface, while on the
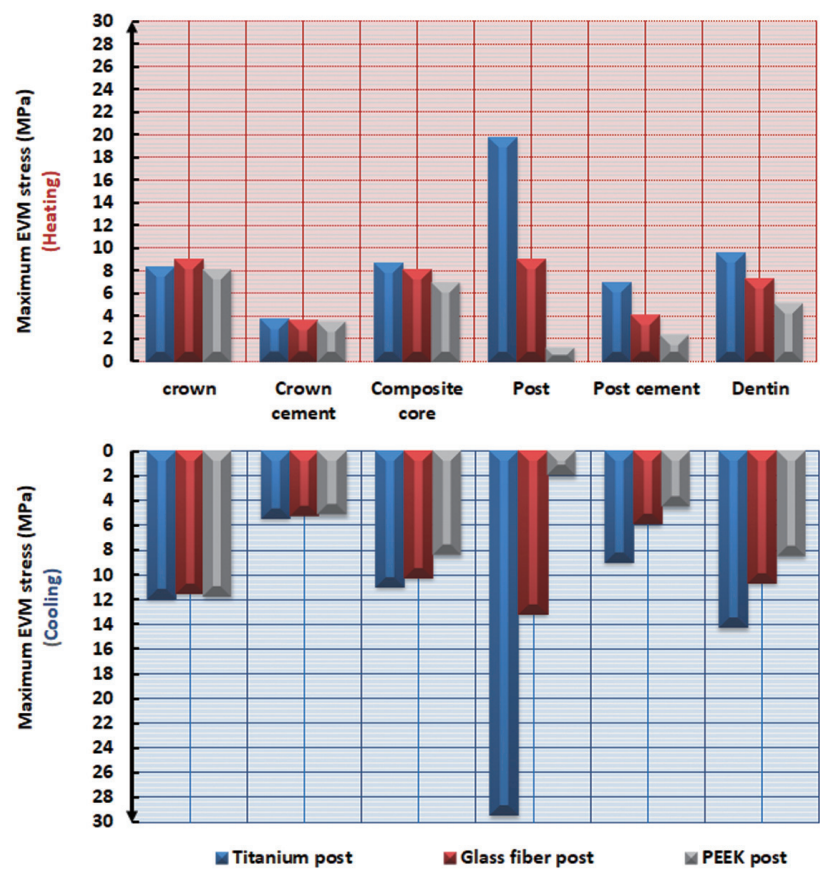

Fig. 9 Maximum EVM stresses on six tissue component after thermal application. 


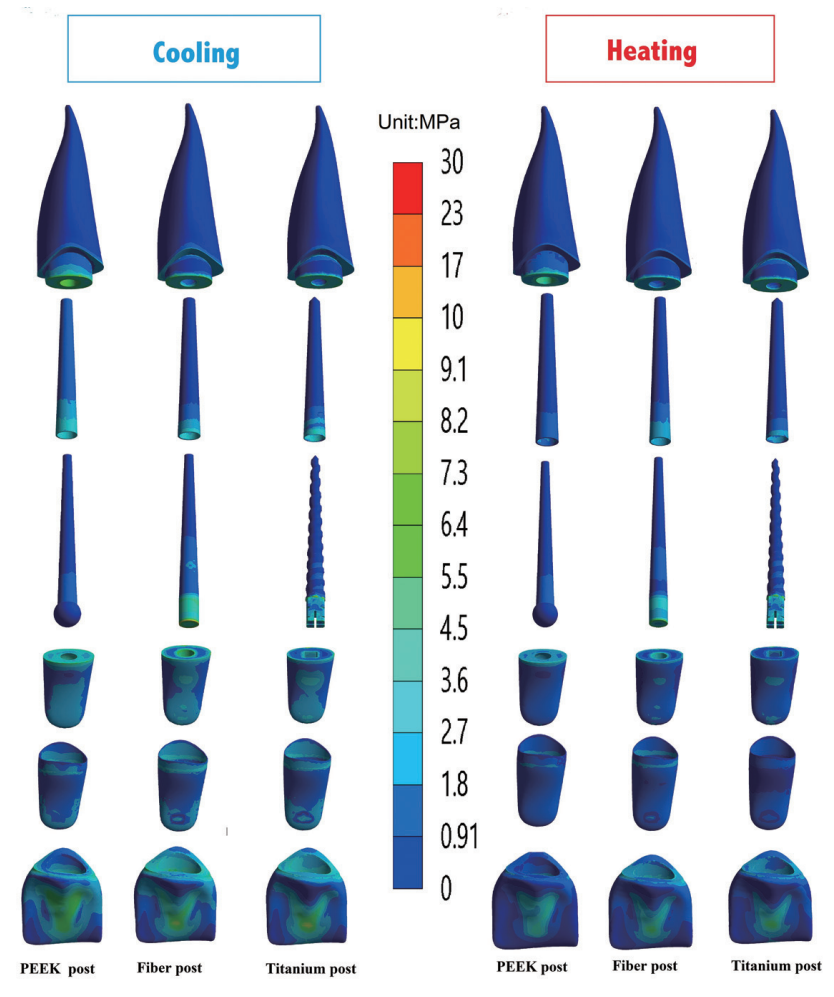

Fig. 10 Stress distributions in $\mathrm{MPa}$ of different tissue components of each post group after cold and hot applications at the end of 21 st second.

core located on the cervical edge with the exception for the post layer, where the position of maximum EVM stress is located on different area in each group. In the titanium post group, the largest stress situated on the labial surface of the post head, a tip of the head in fiber post group, and finally the maximum stress is distributed in larger areas on the neck of a post in PEEK post group.

\section{DISCUSSION}

The risk of tooth fracture is an undesirable incident usually related to insufficient coronal tooth structure after endodontic treatment ${ }^{67,68)}$. Rebuilding of the tooth structure by a post prior to crown restoration sometimes is mandatory to provide a stable and solid restoration of the tooth ${ }^{69,70)}$.

The present study investigated the effect of prefabricated post materials and head design on the amount and distribution of stress created by masticatory and thermal loads on each layer of the post-endodontic restoration system using 3D FEA.

Various methods are used to analyze stress distribution in post-core-restored endodontically treated tooth but the applicability of stress analyses is difficult in vivo this might attribute to difference in mechanical and physical properties of post-core-restored endodontically treated tooth tissues making it difficult to control related factors like amount of remaining tooth structure, load direction, and magnitude, tooth position...etc. On the other hand in-vitro tests the simulation of the oral environment is impossible ${ }^{71-73)}$. To overcome these difficulties, FEA was used in this study to simulate the natural condition in the complex design. In addition, EVM stress have been used for evaluating the stress distribution on important area as it combines normal and shear stresses at a given point which can lead to failure due to the brittle nature of tooth tissues ${ }^{74}$.

Recently, high-performance PEEK polymer has been successively used in dentistry as indirect extra-coronal restorations ${ }^{12,75)}$. Its application as indirect intra-coronal restoration is promising since it has elastic modulus close to dentin $^{37)}$, but their use as cast post or endocrown is still needed laboratory preparation which is expensive and time-consuming. In this respect fabricating a large number of PEEK either by milling or pressing procedure with standardized geometry getting the advantage of appropriate mechanical strength of the material that can be manipulated easily in the clinic during the application, is possible to save time and money.

The post design has the major effect on stress concentration which in turn depend on material properties of the post whether the retention of the post can be achieved with adhesive luting cement or the post derived their primary retention directly from the root dentin by the use of threads ${ }^{2}$. In order to assess the influence of post head design on the stress distribution of endodontically restored tooth, the magnitudes of EVM stresses under mechanical loading conditions were examined. It can be concluded from the results, the head design of the post has a dramatic effect on stress concentration on the core material, and the maximum stresses are mainly located at the line angles even after reducing the sharp edges by inducing fillets to the head design. As a consequence, these stress concentration areas act as a predisposing factor to initiate a crack in the core structure that ends with fracture. This is in a good agreement with the findings of the study ${ }^{24)}$ that concluded using ball-head metal post reduce stress concentration in the core material, however, a ball-head metal post is proved to be less retentive ${ }^{76)}$, but this is not a problem in case of PEEK post, as later can bond chemically to composite core ${ }^{77)}$.

Regarding the effect of post material to the tooth structure and remaining restorative materials, the maximum values of EVM stress in the dental postendodontic restoration system was seen in titanium post, followed by glass fiber post and PEEK posts. This difference is due to the different material properties of the posts like elastic modulus ${ }^{34,78,79)}$. Biomechanically, post with mechanical properties closer to dentin allows the restored system to carry the masticatory load of the natural tooth as a single unit without minimizing stress transfer into the vulnerable root.

In general, all systems of the study show similar behaviors concerning the distribution of stress on each component of the model, and the effect of type of post was significant on the component of the model from the 
crown until cementum, while the type of post did not influence periodontal ligament and the maxillary bone. This is due to the property of the periodontal ligament, as it contributes to the attenuation of any stresse ${ }^{80,81)}$.

Furthermore, the position and magnitude of stress concentration in the post-dentin interface are very important as it determines the position of future crack progression in dentin shifting the fracture pattern towards repairable fractures is a well-known phenomenon when the position of maximum stress is located above the level of the bone ${ }^{7,8}$. It was found that the stresses in PEEK post and glass fiber post were located above the bone level while in the titanium post located in the middle third of the root. These results are consistent with the findings reported previously ${ }^{32,34,82,83)}$ and other researcher ${ }^{84}$ have pointed out that PEEK endocrown distribute the stresses more evenly in contrast to rigid materials which produce stress concentrations at critical areas that might cause cohesive failures in the endocrown and dentin.

It should be pointed out in the present study that the interface between the post and the composite core considered adhesively bonded to mimic the clinical situation where the post bonded either mechanically, or chemically by bonding agents to the core without sliding or frictional movements. As it mentioned by He in 2016; an accurate FEA model of adhesive bonded joint is able to predict failure in the adhesive and at the adhesiveadherent interfaces, and also account for full non-linear material behavior ${ }^{85}$.

Mechanical and thermal stress distribution in the complex geometry of endodontically treated tooth restored with a post, depending on the geometry, physical and thermal properties of different materials and dental tissues. However, the variable stress gradient can contribute to damage the bonding system and cracking of the filling material and remaining dental tissues as well ${ }^{36,86)}$.

In the present investigation, post materials with a low thermal conductivity increased the thermal gradient between the outer and the inner region in a given time. That is to say glass fiber posts produced a higher temperature gradient, followed by PEEK post, and titanium post. This is in agreement with previous findings ${ }^{39,62)}$. It is obvious that this difference can contribute to the loosening of an endodontic post with time, which is the main type of failure in fiber-reinforced $\operatorname{posts}^{87)}$.

Overall, temperature changes and resulting stresses on restorative materials and remaining tooth layers induced by the cold thermal loading simulations were found to be higher than those of hot thermal loadings. This result was in agreement with the other studies $^{30,60,86)}$, as they pointed out that the tensile stress occurs on the surface of restoration as a result of the temperature difference and larger convection coefficient during cold thermal loading may increase the risk of failure compared to hot thermal loading.

Based on simulation results, the effect of the type of the post was more obvious on dentin, post luting cement, and the post itself. It can be also concluded from the results that titanium post produced the highest stress followed by the group restored by fiber post. The outcomes of this study corroborate earlier findings which have revealed that metallic post yields larger stresses than metal-free posts ${ }^{32,41,64)}$. On the other hand, in PEEK post the resulted stresses were homogeneously distributed over larger areas resulting in the least stress concentration.

It should be noted that the simulation materials of the restorative parts and oral structures used in this study were considered to be linearly elastic, homogeneous, isotropic, and ideally bonded, which is not absolutely same as that of natural tooth structure and supporting tissues which they present heterogeneous and anisotropic behaviors ${ }^{32,60)}$ However, to guarantee the accuracy of the finding, direct comparison between the results of FEA study and clinical trial with in-vitro studies are necessary to support or modify the outcome of the present study and evaluate the combined effects of thermal changes and mechanical loading.

\section{CONCLUSIONS}

Within the limitations of this study, the following conclusions could be drawn:

1. A proper design of the post head produces a more benign stress distribution and minimizes the risk of failure after post-endodontic treatment.

2. Endodontically treated teeth restored with PEEK prefabricated posts may survive masticatory and oral thermal loading stresses better than titanium and glass fiber post.

3. PEEK prefabricated post, exhibited a favorable stress distribution pattern at the intra-radicular dentin, indicating a lower possibility of vertical root fracture than stiffer post materials.

4. Glass fiber post produced the highest temperature gradient between components of the restored tooth model, followed by PEEK post, while titanium post produced the least temperature gradient.

5. Cold thermal loading produced larger temperature changes and stress concentrations than hot thermal loading regardless of the type of post used.

The results of this study can be considered of clinical significance, providing a better understanding of the stress and thermal distribution between the components of post endodontic restoration to select the most appropriate combination of materials to meet the overall system objective.

\section{ACKNOWLEDGMENTS}

The authors sincerely acknowledge the College of Dentistry, University of Sulaimani, for supporting the project, the author also acknowledge the Dental Center for providing CBCT scan with mimics image processing software. 


\section{REFERENCES}

1) Polesel A. Restoration of the endodontically treated posterior tooth. G Ital Endod 2014; 28: 2-16.

2) Hargrevaves KM, Berman LH. Cohen pathways of the Pulp. 11th ed. St.Louis,Missouri: Elsevier; 2016. p.824.

3) Gutmann JL. Grossman's Endodontic Practice-13th ed. J Conserv Dent 2016; 19: 494.

4) Pegoretti A, Fambri L, Zappini G, Bianchetti M. Finite element analysis of a glass fibre reinforced composite endodontic post. Biomaterials 2002; 23: 2667-2682.

5) Vachhani KA, Asnani MM. "Evaluation of fracture strength of teeth restored with different types of posts luted with different luting cements": an in vitrostudy. Niger J Clin Pract 2015; 18: 411-415.

6) Lanza A, Aversa R, Rengo S, Apicella D, Apicella A. 3D FEA of cemented steel, glass and carbon posts in a maxillary incisor. Dent Mater 2005; 21: 709-715.

7) A Alharbi F, Nathanson D, Morgano SM, Baba NZ. Fracture resistance and failure mode of fatigued endodontically treated teeth restored with fiber-reinforced resin posts and metallic posts in vitro . Dent Traumatol 2014; 30: 317-325.

8) Mahmoudi M, Saidi A, Gandjalikhan Nassab SA, Hashemipour MA. A three-dimensional finite element analysis of the effects of restorative materials and post geometry on stress distribution in mandibular molar tooth restored with postcore crown. Dent Mater J 2012; 31: 171-179.

9) Lee KS, Shin JH, Kim JE, Kim JH, Lee WC, Shin SW, et al. Biomechanical evaluation of a tooth restored with high performance polymer PEKK post-core system: A 3D finite element analysis. Biomed Res Int 2017; 2017: 1373127.

10) Huang T-JG, Schilder H, Nathanson D. Effects of moisture content and endodontic treatment on some mechanical properties of human dentin. J Endod 1992; 18: 209-215.

11) Gan K, Liu H, Liu X, Niu D. Research progress of polyether ether ketone biocomposites. Ann materials Sci Eng 2015; 2: 1020 .

12) Najeeb S, Zafar MS, Khurshid Z, Siddiqui F. Applications of polyetheretherketone (PEEK) in oral implantology and prosthodontics. J Prosthodont Res 2016; 60: 12-19.

13) Rocha RF, Anami LC, Campos TM, Melo RM, Souza RO, Bottino MA. Bonding of the polymer polyetheretherketone (PEEK) to Human dentin: Effect of surface treatments. Braz Dent J 2016; 27: 693-699.

14) Song CH, Choi JW, Jeon YC, Jeong CM, Lee SH, Kang ES, et al. Comparison of the microtensile bond strength of a polyetherketoneketone (PEKK) tooth post cemented with various surface treatments and various resin cements. Materials (Basel) 2018; 11: 916.

15) Kurtz SM. Chapter 15 -Development and Clinical Performance of PEEK Intervertebral Cages. In: Kurtz SM, editor. PEEK Biomaterials Handbook 2nd ed: William Andrew Publishing; 2019. p. 263-280.

16) Rahmitasari F, Ishida $Y$, Kurahashi K, Matsuda T, Watanabe M, Ichikawa T. PEEK with reinforced materials and modifications for dental implant applications. Dent J (Basel) 2017; 5: 35.

17) Zoidis P, Bakiri E, Polyzois G. Using modified polyetheretherketone (PEEK) as an alternative material for endocrown restorations: A short-term clinical report. J Prosthet Dent 2017; 117: 335-339.

18) Urwyler P, Zhao X, Pascual A, Schift H, Müller B. Tailoring surface nanostructures on polyaryletherketones for loadbearing implants. Eur J Nanomed 2014; 6: 37-46.

19) Alsadon O, Wood D, Patrick D, Pollington S. Comparing the optical and mechanical properties of PEKK polymer when $\mathrm{CAD} / \mathrm{CAM}$ milled and pressed using a ceramic pressing furnace. J Mech Behav Biomed Mater 2019; 89: 234-236.

20) Moshonov J, Slutzky-Goldberg I, Gottlieb A, Peretz B. The effect of the distance between post and residual gutta-percha on the clinical outcome of endodontic treatment. J Endod 2005; 31: 177-179.

21) Slutzky-Goldberg I, Slutzky H, Gorfil C, Smidt A. Restoration of endodontically treated teeth review and treatment recommendations. Int J Dent 2009; 2009: 150251.

22) Bacchi A, Dos Santos MBF, Pimentel MJ, Caetano CR, Sinhoreti MAC, Consani RLX. Influence of post-thickness and material on the fracture strength of teeth with reduced coronal structure. J Conserv Dent 2013; 16: 139-143.

23) Heydecke G, Butz F, Strub JR. Fracture strength and survival rate of endodontically treated maxillary incisors with approximal cavities after restoration with different post and core systems: an in-vitro study. J Dent 2001; 29: 427433.

24) $\mathrm{Al}$-Zahawi. Influence of prefabricated post screw head design on the stress pattern in the core and crown. Finite element stress analysis study. Sulaimani Dent J 2015; 2: 77-82.

25) Yoon HG, Oh HK, Lee DY, Shin JH. 3-D finite element analysis of the effects of post location and loading location on stress distribution in root canals of the mandibular 1st molar. J Appl Oral Sci 2018; 26.

26) Chen A, Feng X, Zhang Y, Liu R, Shao L. Finite element analysis of stress distribution in four different endodontic post systems in a model canine. Biomed Mater Eng 2015; 26 Suppl 1: S629-635.

27) Daneshkazemi A, Davari A, Akbari MJ, Davoudi A, Badrian H. Effects of thermal and mechanical load cycling on the dentin microtensile bond strength of Single Bond-2. J Int Oral Health 2015; 7: 9-13.

28) Oskui IZ, Ashtiani MN, Hashemi A, Jafarzadeh H. Thermal analysis of the intact mandibular premolar: a finite element analysis. Int Endod J 2013; 46: 841-846.

29) Lopes MB, Yan Z, Consani S, Gonini Júnior A, Aleixo A, McCabe JF. Evaluation of the coefficient of thermal expansion of human and bovine dentin by thermomechanical analysis. Braz Dent J 2012; 23: 3-7.

30) Cornacchia TP, Las Casas EB, Cimini CA Jr, Peixoto RG. 3D finite element analysis on esthetic indirect dental restorations under thermal and mechanical loading. Med Biol Eng Comput 2010; 48: 1107-1113.

31) Hu T, Cheng R, Shao M, Yang H, Zhang R, Gao Q, Guo L. Application of Finite Element analysis in root canal therapy. Finite Element Analysis, David Moratal, IntechOpen, DOI: 10.5772/9994. Available from: https://www.intechopen.com/ books/finite-element-analysis/application-of-finite-elementanalysis-in-root-canal-therapy.

32) Chieruzzi M, Pagano S, Cianetti S, Lombardo G, Kenny JM, Torre L. Effect of fibre posts, bone losses and fibre content on the biomechanical behaviour of endodontically treated teeth: 3D-finite element analysis. Mater Sci Eng C Mater Biol Appl 2017; 74: 334-346.

33) Rodrigues MP, Soares PBF, Valdivia A, Pessoa RS, Verissimo $\mathrm{C}$, Versluis A, et al. Patient-specific finite element analysis of fiber post and ferrule design. J Endod 2017; 43: 1539-1544.

34) Lee KS, Shin JH, Kim JE, Kim JH, Lee WC, Shin SW, et al. Biomechanical evaluation of a tooth restored with high performance polymer PEKK post-core system: A 3D finite element analysis. Biomed Res Int 2017; 2017: 1-9.

35) Hussein FA, Salloomi KN, Abdulrahman BY, Al-Zahawi AR, Sabri LA. Effect of thread depth and implant shape on stress distribution in anterior and posterior regions of mandible bone: A finite element analysis. Dent Res J 2019; 16: 200207.

36) Er Özgur, Yaman SD, Hasan M. Finite element analysis of the effects of thermal obturation in maxillary canine teeth. Oral Surg Oral Med Oral Pathol Oral Radiol Endod 2007; 104: 277-286.

37) Çelik Köycü B, İmirzalıŏglu P. Heat transfer and thermal 
stress analysis of a mandibular molar tooth restored by different indirect restorations using a three-dimensional finite element method. J Prosthodont 2017; 26: 460-473.

38) Varghese S, Ariga P, Padmanaban TV, Subramanian R. A finite element thermal analysis of various dowel and core materials. Indian J Dent Res 2012; 23: 176-181.

39) Yang HS, Lang LA, Guckes AD, Felton DA. The effect of thermal change on various dowel-and-core restorative materials. J Prosthet Dent 2001; 86: 74-80.

40) Wood SA, Strait DS, Dumont ER, Ross CF, Grosse IR. The effects of modeling simplifications on craniofacial finite element models: the alveoli (tooth sockets) and periodontal ligaments. J Biomech 2011; 44: 1831-1838.

41) Deger Y, Adiguzel O, Yigit Ozer S, Kaya S, Seyfioglu Polat Z, Bozyel B. Evaluation of temperature and stress distribution on 2 different post systems using 3-dimensional finite element analysis. Med Sci Monit 2015; 21: 3716-3721.

42) Dal Piva AMdO, Tribst JPM, Souza ROdAe, Borges ALS. Influence of alveolar bone loss and cement layer thickness on the biomechanical behavior of endodontically treated maxillary incisors: A 3-dimensional finite element analysis. J Endod 2017; 43: 791-795.

43) Sang YH, Hu HC, Lu SH, Wu YW, Li WR, Tang ZH. Accuracy assessment of three-dimensional surface reconstructions of in vivo teeth from cone-beam computed tomography. Chin Med J 2016; 129: 1464-1470.

44) Kotb S, Shaker A, Halim C. Fatigue resistance and 3D finite element analysis of machine-milled ceramic occlusal veneers with new preparation designs versus conventional design: an in vitro study. F1000Research 2019; 8: 1038.

45) Nelson SJ. Wheeler's dental anatomy, physiology, and occlusion. 10th ed. St. Louis,Mo.: Elsevier; Saunders. p.105.

46) Shaikh SY, Shaikh SS. Direct linear measurement of root dentin thickness and dentin volume changes with post space preparation: A cone-beam computed tomography study. Contemp Clin Dent 2018; 9: 77-82.

47) Brokos YSM, Bortolotto Ibarra T, Krejci I. Evaluation of enamel thickness of upper anterior teeth in different age groups by dental cone beam computed tomography scan in vivo. Int J Adv Case Reports 2015; 2: 1396-1409.

48) Yamamoto T, Hasegawa T, Yamamoto T, Hongo H, Amizuka N. Histology of human cementum: Its structure, function, and development. Jpn Dent Sci Rev 2016; 52: 63-74.

49) Tuna M, Sunbuloglu E, Bozdag E. Finite element simulation of the behavior of the periodontal ligament: A validated nonlinear contact model. J Biomech 2014; 47: 2883-2890.

50) Kanjanaouthai A, Mahatumarat K, Techalertpaisarn P, Versluis A. Effect of the inclination of a maxillary central incisor on periodontal stress: finite element analysis. Angle Orthod 2012; 82: 812-819.

51) Kim HJ, Yu SK, Lee MH, Lee HJ, Kim HJ, Chung CH. Cortical and cancellous bone thickness on the anterior region of alveolar bone in Korean: a study of dentate human cadavers. J Adv Prosthodont 2012; 4: 146-152.

52) Nahas-Scocate AC, de Siqueira Brandao A, Patel MP, LipiecXimenez ME, Chilvarquer I, do Valle-Corotti KM. Bone tissue amount related to upper incisors inclination. Angle Orthod 2014; 84: 279-285.

53) Ravindra SV, Mamatha GP, Sunita JD, Balappanavar AY, Sardana V. Morphometric analysis of pulp size in maxillary permanent central incisors correlated with age: An indirect digital study. J Forensic Dent Sci 2015; 7: 208-214.

54) Sabri L, Hussein F, AL-Zahawi A, Abdulrahman B, Salloomi K. Biomechanical finite element analysis of a single implant threaded in anterior and posterior regions of maxilla bone. Indian J Dent Res 2020; 31: 203-208.

55) Mozini AC, Vansan LP, Sousa Neto MD, Pietro R. Influence of the length of remaining root canal filling and post space preparation on the coronal leakage of Enterococcus faecalis.
Braz J Microbiol 2009; 40: 174-179.

56) Rao N. Advanced Endodontics. New Delhi, India: Jaypee brothers medical publishers; 2009. p.254.

57) Mirmohammadi H, Gerges E, Salameh Z, Wesselink PR. Effect of post diameter and cement thickness on bond strength of fiber posts. Quintessence Int 2013; 44: 801-810.

58) Rosenstiel SF, Land MF, Fujimoto J. Contemporary of fixed prosthodontics. St. Louis, Mo: Mosby; Elsevier.2006. p.284.

59) Kious AR, Roberts HW, Brackett WW. Film thicknesses of recently introduced luting cements. J Prosthet Dent 2009; 101: 189-192.

60) Celebi AT, Icer E, Eren MM, Baykasoglu C, Mugan A, Yildiz E. Thermal-stress analysis of ceramic laminate veneer restorations with different incisal preparations using microcomputed tomography-based 3D finite element models. J Mech Behav Biomed Mater 2017; 75: 302-313.

61) Benazzi S, Nguyen HN, Kullmer O, Kupczik K. Dynamic modelling of tooth deformation using occlusal kinematics and finite element analysis. PLoS One 2016; 11: e0152663.

62) Toparli M, Sasaki S. Finite element analysis of the temperature and thermal stress in a postrestored tooth. J Oral Rehabil 2003; 30: 921-926.

63) Adıgüzel Ö, Yigit-Ozer S, Bahşi E, Yavuz I. Finite element analysis of endodontically treated tooth restored with different posts under thermal and mechanical loading. Int Dent Res 2011; 1.

64) Egilmez F, Nalbant L. Comparison of the effect of thermal stresses on tooth-colored posts, cores and tooth structures by finite element analysis. Cumhuriyet Dent J 2012; 15: 118129.

65) Guler MS, Guler C, Cakici F, Cakici EB, Sen S. Finite element analysis of thermal stress distribution in different restorative materials used in class V cavities. Niger J Clin Pract 2016; 19: $30-34$

66) Eberhart RC, Shitzer A. Heat Transfer in Medicine and Biology: Analysis and Applications. NewYork,US: Springer; 2012. p.324-325.

67) Carvalho MA, Lazari PC, Gresnigt M, Del Bel Cury AA, Magne P. Current options concerning the endodonticallytreated teeth restoration with the adhesive approach. Braz Oral Res 2018; 32: e74.

68) Goracci C, Ferrari M. Current perspectives on post systems: a literature review. Aust Dent J 2011; 56: 77-83.

69) Nanda SM, Nanda T, Yadav K, Sikka N. Fibre post \& all ceramic crown - a simple approach to the perfect smile. Sch J Dent Sci 2015; 2: 247-249.

70) Cheung W. A review of the management of endodontically treated teeth. Post, core and the final restoration. J Am Dent Assoc 2005; 136: 611-619.

71) Al-Omiri MK, Mahmoud AA, Rayyan MR, Abu-Hammad O. Fracture resistance of teeth restored with post-retained restorations: an overview. J Endod 2010; 36: 1439-1449.

72) Machado J, Almeida P, Fernandes S, Marques A, Vaz M. Currently used systems of dental posts for endodontic treatment. Procedia Struc Integrity 2017; 5: 27-33.

73) Schwartz RS, Robbins JW. Post placement and restoration of endodontically treated teeth: a literature review. J Endod 2004; 30: 289-301.

74) Amarante MV, Pereira MV, Darwish FA, Camarão AF. Stress prediction in a central incisor with intra-radicular restorations. Mat Res 2011; 14: 189-194.

75) Skirbutis G, Dzingute A, Masiliunaite V, Sulcaite G, Zilinskas J. A review of PEEK polymer's properties and its use in prosthodontics. Stomatologija 2017; 19: 19-23.

76) Zalkind M, Shkury S, Stern N, Heling I. Effect of prefabricated metal post-head design on the retention of various core materials. J Oral Rehabil 2000; 27: 483-487.

77) Stawarczyk B, Taufall S, Roos M, Schmidlin PR, Lumkemann $\mathrm{N}$. Bonding of composite resins to PEEK: the influence of 
adhesive systems and air-abrasion parameters. Clin Oral Investig 2018; 22: 763-771.

78) Boksman L, Pameijer CH, Broome JC. The clinical significance of mechanical properties in retentive posts. Compend Contin Educ Dent 2013; 34: 446-455.

79) Plotino G, Grande NM, Bedini R, Pameijer CH, Somma F. Flexural properties of endodontic posts and human root dentin. Dent Mater 2007; 23: 1129-1135.

80) Palamidakis F, Panou A, Papadokostaki K, Leontakianakos G, Stathopoulos V, Kontakiotis E. Device and materials for in vitro evaluation of forces developed to teeth and periodontal structures during dental practices. J Dent Biomech 2013; 4: 1758736013503648.

81) Ou KL, Chang CC, Chang WJ, Lin CT, Chang KJ, Huang HM. Effect of damping properties on fracture resistance of root filled premolar teeth: A dynamic finite element analysis. Int Endod J 2009; 42: 694-704.

82) Madfa AA, Al-Hamzi MA, Al-Sanabani FA, Al-Qudaimi NH, Yue X-G. 3D FEA of cemented glass fiber and cast posts with various dental cements in a maxillary central incisor. SpringerPlus 2015; 4: 598.

83) Kumar P, Rao R. Three-dimensional finite element analysis of stress distribution in a tooth restored with metal and fiber posts of varying diameters: An in-vitro study. J Conserv Dent 2015; 18: 100-104.

84) Ghajghouj O, Taşar-Faruk S. Evaluation of fracture resistance and microleakage of endocrowns with different intracoronal depths and restorative materials luted with various resin cements. Materials 2019; 12: 2528.

85) He X. A review of finite element analysis of adhesively bonded joints. Int J Adhes Adhes 2011; 31: 248-264.

86) Pałka K, Bieniaś J, Dębski H, Niewczas A. Finite element analysis of thermo-mechanical loaded teeth.Comput Mater Sci 2012; 64: 289-294.

87) Schmitter M, Hamadi K, Rammelsberg P. Survival of two post systems - five-year results of a randomized clinical trial. Quintessence Int 2011; 42: 843-850. 